\title{
ESTRATEGIAS DE COMUNICACIÓN 2.0 EN EL MERCADO FERIAL DE ESPAÑA, PORTUGAL Y AMÉRICA LATINA
}

\author{
Xosé Manuel Baamonde Silva \\ Universidad de Vigo \\ xbaamonde@uvigo.es \\ Fermín Galindo Arranz \\ Universidad de Santiago de Compostela \\ fermin.galindo@usc.es \\ 1336 Jorge Marinho \\ Universidade de Porto

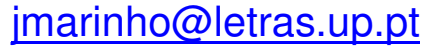

Material original autorizado para su primera publicación en la revista académica REDMARKA. Revista Digital de Marketing Aplicado.

http://doi.org/10.17979/redma.2012.02.08.4762

Recibido: 2 Noviembre 2011

Aceptado: 15 Febrero 2012

\section{Resumen:}

Las ferias son espacios de comunicación. No son sólo centros de negocio y, por tanto, pueden estudiarse bajo un enfoque comunicativo. Esta investigación analiza la utilización de la Web 2.0 y las redes sociales como herramientas de comunicación. Se constata que las organizaciones feriales de la Península Ibérica y de Latinoamérica tienen unas webs orientadas a satisfacer las necesidades de información de los medios de comunicación pero no están preparadas para dialogar directamente con la opinión pública. La mayoría de los espacios en Internet de las organizaciones feriales españolas, portuguesas y latinoamericanas no están aprovechando las posibilidades que ofrece la web 2.0 y las redes sociales para conversar con sus públicos. La gestión de la 
comunicación debe incluir la utilización de las redes sociales, porque ya no es suficiente con estar en Internet, hay que participar en la vida de la red.

Palabras clave: estrategias de comunicación, ferias, web 2.0

\section{Abstract: \\ COMMUNICATION STRATEGIES 2.0 ON THE TRADE FAIR MARKET OF SPAIN, PORTUGAL AND LATIN AMERICA}

The trade fairs are spaces of communication. They are not only business centres and, therefore, they can study under a communicative approach. This investigation analyses the utilisation of the Web 2.0 and the social networks like communication tools. The Iberian Peninsula and o Latin America trade fairs have webs oriented to satisfy the needs of information of the media but not to have a conversation directly with the public opinion. The spaces in Internet of Spanish, Portuguese and Latin American trade fairs organizations are not taking advantage of the possibilities that offers the web 2.0 and the social networks to converse with their publics. The management of communication has to include the utilisation of the social networks, because it is necessary to participate in the life of Internet.

Keywords: communication strategies, fairs, web 2.0,

\section{Resumo:}

ESTRATÉGIAS DE COMUNICAÇÃO 2.0 NO MERCADO FEIRAL DE ESPANHA, PORTUGAL E AMÉRICA LATINA

Os centros de eventos, como as feiras, são espaços de comunicação. Não são apenas centros de negócios e, como tal, podem ser estudados de um ponto de vista comunicativo. Esta investigação analisa a utilização da Web 2.0 e das redes sociais como ferramentas de comunicação. Constata-se que as organizações de feiras da Península lbérica e da América Latina têm as súas webs orientadas para satisfazer as necessidades de informação dos meios de comunicação social, mas não estão preparadas para dialogar diretamente com a opinião pública. A maioria dos espaços na Internet das organizações de 
feiras espanholas, portuguesas e latino-americanas não está aproveitando as possibilidades que a Web 2.0 e as redes sociais oferecem para conversar com os seus públicos. A gestão da comunicação deve incluir a utilização das redes sociais, dado que já não é suficiente estar na Internet, há que participar na vida da Rede.

Palavras-chave: estratégias de comunicação, feiras, Web 2.0, 


\section{El concepto de feria a lo largo de la historia}

El término feria tenía, en su origen, una acepción de festival religioso, celebrado en las proximidades de un convento o iglesia. Paulatinamente, estas fiestas aparecen unidas a prácticas mercantiles y, poco a poco, las transacciones comerciales prevalecen sobre los aspectos religiosos. Cuando el volumen del comercio era pequeño y el transporte y las comunicaciones difíciles fue de gran ayuda para los vendedores saber que si tenían sus productos en un lugar y en un día acordado encontrarían los compradores reunidos en aquel punto. Por lo tanto, este conocimiento centralizaba la oferta y demanda, ahorraba tiempo y estimulaba la venta.

Las ferias desempeñaron un papel importante en el desarrollo del comercio a lo largo de la historia. Con la aparición de la moneda se reforzó el aspecto transaccional de las mismas, pero fue con la Revolución Industrial de siglo XIX, cuando se convirtieron en centros de exposición donde cada nación exhibía sus productos (Cevera, Franco y García, 2001 p. 131). Pretendía promover los avances tecnológicos de un país e impulsar la actividad comercial fuera de sus fronteras (Jiménez, Cazorla y Linares, 2002, pp. 61-71).

Las Exposiciones Universales pueden considerarse el precedente más directo de la actual concepción de las ferias, certámenes y salones profesionales. Los estudiosos señalan la celebrada en el Cristal Palace de Londres, en 1851 y que duró siete meses, con 14.000 expositores y más de 6 millones de visitantes, como el inicio de la actividad ferial moderna. En 1855, se desarrolló otra convocatoria similar en París, con 23.954 expositores y 5,1 millones de visitantes.

Después de la segunda Guerra Mundial los países industrializados se dieron cuenta de la necesidad de tener una serie de citas periódicas de ámbito nacional, que, además de dar a conocer los avances en cada uno de sus productos, sirviesen de contacto directo entre empresario y cliente para su 
promoción. Empiezan, pues, a construirse recintos, normalmente en las afueras de las ciudades, y paulatinamente van creciendo hasta las dimensiones actuales, en las que, junto a una superficie en constante aumento, sus certámenes ocupan todos los días del año.

Una de las aspiraciones de este tipo de edificios es lograr una enorme cantidad de espacio en planta, sin necesidad de interrumpirla con ningún tipo de soportes (Rico, 2005, p. 47). En la segunda mitad del siglo XX se inicio el fenómeno de las ferias en el sentido moderno de convocatoria monográfica 0 sectorial, a partir de las ferias industriales. El desarrollo económico hizo preciso la especialización de los encuentros, que se orientaron a un determinado sector económico y a un colectivo profesional específico. El siguiente paso, fue su creciente internacionalización (Lucas, 2004).

La investigación sobre los distintos ámbitos del sector ferial no es muy abundante y las diversas definiciones del término feria se refieren, fundamentalmente, a aspectos relacionados con el marketing. Los factores comunicativos de este fenómeno han recibido poca atención desde la perspectiva académica e investigadora. Como indican los profesores de la Universidad de Mondragón, Mikel Mesonero y Fermín Garmendia (2004, p.111), la principal función de las ferias "que no única, es comunicacional, trasmitiendo flujos de información entre oferta y demanda".

Fernando Jaén (1995, p. 17) destaca la perspectiva comercial al indicar que una feria es la organización sobre un espacio físico de encuentro entre expositores (y sus productos) y visitantes ( $y$, por lo menos, sus expectativas de ver lo expuesto). Otros autores (Hansen, 1996; Cevera, Franco y García, 2001) también indican que el éxito de estas convocatorias radica en la capacidad que tienen de reunir a la mayor parte de la oferta y la demanda del sector representado en un momento concreto. Estas concepciones, aunque no aluden claramente a valores comunicativos, implícitamente, se basan en el 
intercambio de información entre los expositores/oferta y los visitantes/demanda.

Fernando Le Monnier (1994, p.13) define las "exposiciones profesionales como instrumentos de marketing que favorecen y aceleran los procesos de venta. Se trata de un medio privilegiado de presentación de productos y servicios ante un gran número de clientes, usuarios, competidores, prescriptores y medio de comunicación en un periodo de tiempo en un espacio reducido". En esta acepción, la venta es el objetivo final, sin embargo, también destaca la capacidad que tienen de reunir a los distintos públicos de un determinado sector, así como a los medios de comunicación, en un espacio y tiempo definido, facilitando el intercambio y el encuentro entre los distintos actores participantes en el ámbito representado.

Fernando Navarro (2001, p. 26), incide una vez más en su concepción de la feria como un elemento comercial, generalmente anual, en el que durante unos cuantos días oferta y demanda concurren en un mismo lugar y tiempo. Además, los expositores y visitantes participantes pueden intercambiar opiniones, informarse y negociar. Este experto en estrategias de marketing aplicadas al mundo ferial introduce los intercambios informativos como un elemento esencial junto a los objetivos mercantiles del evento.

En la misma línea Enrique Pérez del Campo (2002, p. 93), profesor de la Universidad Complutense, observa las ferias como un medio de comunicación comercial no convencional, cuya principal fortaleza radica en la capacidad de concitar el interés de públicos objetivos en el espacio físico específico y propio, en un tiempo reducido. Las ferias y exposiciones son eventos organizados para la promoción de intercambios de bienes, servicios e información, basados en la concentración física y temporal de un sector de actividad concreta.

Las aportaciones de Juan Puchalt (2001, pp. 43-44) se centran en un punto de vista de márketing, pero también está presente la importancia de la 
comunicación y la información en el proceso ferial. El experto en organización ferial, José Luis Latorre (1990, p. 11), indica que son un catalizador de aquellas actividades de la empresa que precisan de la comunicación para ser llevadas a cabo. Como tal catalizador, intensifican las actividades y permiten que estas se desarrollen a un ritmo mayor y en presencia de la competencia. En síntesis, las ferias sirven de acelerador del conjunto de procesos que tienen lugar por la interacción de la empresa en el mercado.

Una perspectiva más centrada en los aspectos comunicativos, la ofrece Baamonde (2009, p. 247), para quien las ferias son espacios públicos de comunicación profesional, en la que todos los actores de un determinado sector se reúnen, en un lugar definido, durante un tiempo concreto, para intercambiar información y conocimiento y hacer negocio.

Estas aportaciones demuestran la importancia de la relación entre comunicación y feria, de tal forma que, pese a que los investigadores no han centrado su análisis en ellos, los elementos comunicativos siempre han estado presentes en el fenómeno ferial.

En muchas ciudades, especialmente de los países con mayor tradición ferial, se presta gran atención a la construcción, mantenimiento y ampliación de los recintos feriales, no sólo para favorecer dicha actividad por sí misma, sino también porque es entendida como una actividad generadora de negocio y empleo para el entorno geográfico en el que se desarrolla la misma y, por ello, es respaldada y fomentada por las diferentes administraciones (Puchalt, 2008:30). El funcionamiento ecológico de los referidos edificios es una preocupación creciente por pare de las respectivas administraciones.

Este artículo pretende profundizar en el escenario actual del mercado ferial en la Península Ibérica y en América Latina para comprobar la utilización de las herramientas que ponen a disposición de los organizadores feriales la denominada web 2.0 y las redes sociales, con el consiguiente aprovechamiento 
de las oportunidades para vincularse con sus potenciales clientes: expositores y visitantes. La aparición de Internet está provocando cambios sustanciales en la forma en que los públicos de los recintos feriales se relacionan - o pueden y quieren relacionarse- con los organizadores de ferias, ya que permiten una interacción directa y una comunicación bidireccional.

\section{Metodología}

El objeto del presente estudio es la utilización de los recursos de la Web 2.0 y las redes sociales por parte de las organizaciones feriales en España, Portugal y América Latina. La hipótesis que se pretende comprobar es si los organizadores feriales iberoamericanos están adoptando las medidas necesarias para explotar las posibilidades de la Web 2.0 y las redes sociales como herramientas de comunicación, que contribuya a una mayor consolidación de las ferias como espacios de intercambio económico y de conocimiento, tanto en la Península Ibérica como en Hispanoamérica.

Entendemos que deberían aprovecharse dichas oportunidades para generar una comunicación más interactiva y participativa entre los distintos actores feriales, así como una relación permanente entre los distintos públicos de este sector. Así, las organizaciones feriales podrían aglutinar a todos los actores de cada ámbito específico en torno a esa convocatoria y mantener una comunicación constante con empresas y profesionales.

La metodología utilizada en esta investigación consta de dos fases fundamentales. Un estudio del contenido de las webs de los miembros de AFE (Asociación de Ferias Españolas), APFC (Asociación Portuguesa de Ferias y Congresos) y AFIDA (Asociación Internacional de Ferias de América Latina), así como de su participación ren redes sociales. Dado que el mercado ferial en Portugal no está lo suficientemente desarrollado, a la hora de analizar los datos, englobamos los resultados conjuntamente a los españoles, para comparar la situación en la Península lbérica y en Latinoamérica. 
La segunda fase consistió en un período de participación observante en los tres organizadores feriales más importantes del Arco Atlántico (BEC -Bilbao Exhibition Center-, Exponor -Feria Internacional de Porto- e Ifevi -Instituto Ferial de Vigo-). Esta actuación, acompañada de una serie de entrevistas en profundidad a los responsables de la gestión comunicativa de estas entidades, nos permitió conocer sus opiniones sobre las posibilidades de Internet, las principales líneas de sus estrategias de comunicación y su posicionamiento ante los nuevos medios sociales. Se pudo contrastar las líneas de comunicación online de estas entidades, compararlas con el posicionamiento en Internet de los organizadores feriales ibéricos y latinoamericanos; así como sus previsiones para el futuro próximo.

La tendencia actual pasa por contar con ferias tradicionales asociadas a ferias virtuales. Una de las mayores ventajas de las ferias virtuales respecto a las tradicionales, es su capacidad para eliminar los inconvenientes de su duración limitada en el tiempo y espacio geográfico. Esto es, las ferias virtuales están abiertas durante todo el año y permiten a los visitantes conocer a los expositores antes de la feria física tradicional.

En concreto, la feria online le sirve al visitante para organizar su visita al evento físico, ya que previamente ha podido navegar por los diferentes stands y si lo desea puede contactar con los expositores antes de asistir al evento. Por su parte el expositor cuenta con la ventaja añadida de fijar una entrevista con el visitante y optimizar mejor el tiempo de cara a la feria física, planificar el calendario de entrevistas, etcétera. También para los organizadores feriales se produce una mejora en la promoción del evento multiplicando las posibilidades de difusión del mismo.

El presente trabajo pretende dar un paso más y comprobar si los recursos de las redes sociales y otros servicios de la web 2.0 están siendo desarrollados con acierto, tanto por los organizadores feriales de la Península Ibérica como 
por los de América Latina. El sector de ferias y eventos es muy social, móvil y colaborativo, por lo que creemos que dispone de las características necesarias para explotar al máximo estas potencialidades.

\section{El sector ferial en la Península Ibérica y América Latina}

En España, crece la tendencia en el mercado expositivo de lanzar encuentros muy especializados dirigidos a segmentos específicos. BCF Consultors, la empresa de consultoría externa encargada de recoger los datos feriales de AFE del 2010, auditó la cifra de 477 certámenes. En términos numéricos, se mantiene el total de ferias celebradas con un ligero repunte respecto al año anterior. Se han creado nuevas Ferias nacidas de las necesidades de un mercado cada vez más segmentado. Otros datos relevantes, del año 2010, son los casi 3'5 millones de metros cuadrados netos de espacio expositivo, los 10 millones y medio de visitas y casi 58.000 expositores ${ }^{1}$.

Las medidas que está tomando AFE y las entidades que la forman se traducen en una línea progresiva ascendente del sector ferial, que, pese al actual contexto económico desfavorable, se consolida como un mercado sólido y rentable. Las Ferias siguen configurándose como una apuesta segura y de alta rentabilidad para dar respuesta a las necesidades de de las empresas y entidades que realizan la actividad ferial.

La expansión de la actividad ferial ha alcanzado a gran parte del territorio estatal de manera que, lejos de acentuarse las diferencias entre las principales plazas (Madrid, Barcelona y Valencia) y el resto de las zonas geográficas, se está produciendo una mayor regionalización de los certámenes feriales a la vista de la construcción de nuevos recintos en localidades que no son capitales de provincia.

\footnotetext{
${ }^{1}$ Recogido de http://www.afe.es consultado el 6 de septiembre de 2011.
} 
De todas formas, el desarrollo socioeconómico y demográfico de cada área geográfica va a ser lo que determine su crecimiento ferial, y mientras que en unos casos supondrá una apuesta por aquellos sectores en los que prime la presencia de expositores, en otros casos, la oferta ferial irá dirigida a conseguir una mayor afluencia de visitantes, lo que puede ser compatible con un mayor o menor grado de especialización como sucede con los certámenes multisectoriales o en algunas de las más importantes ferias de turismo y ocio que se celebran a nivel nacional (Jiménez y Pemartín, 2008, p. 70).

La evolución de las ferias en Latinoamérica es similar pero con algunos matices y peculiaridades, propias de una región que recibió Influencia de cultura europea, africana e indígena, lo cual genera un "Mosaico Cultural"-2. Países muy jóvenes, establecidos sobre extensos territorios, y con grados de desarrollo muy dispares aún dentro de un mismo Estado. Se trata de un subcontinente de grandes contrastes y niveles de desarrollo económico, social y cultural.

Latinoamérica representa en materia ferial una multiplicidad de realidades complejas e individualidades propias en cada nación. Existen dos grandes grupos de realidades: por un lado los países que han alcanzado cierto nivel de desarrollo en la actividad ferial y, por otro, países que aún se encuentran en vía de desarrollo de su actividad en este sector.

Existe una relación entre los sectores económicos dominantes de América Latina y las ferias y/o exposiciones celebradas en la región. Solamente unos pocos estados cuentan con una arquitectura orientada específicamente al desarrollo ferial. El número de recintos por país difiere de acuerdo al tamaño, población y actividad económica. Brasil, México, Argentina y Colombia son los 4 primeros países según su oferta de recintos y centros de convenciones.

\footnotetext{
${ }^{2}$ Recogido de http://www.afida.org/, consultado el 6 de septiembre de 2011.
} 
Tradicionalmente, en algunos países como México, los recintos se convierten únicamente en arrendatarios de espacios a otras compañías, que son los que realmente organizan las ferias. Esta tendencia está cambiando y los recintos están participando en la realización de los eventos, convirtiéndose en organizadores feriales.

La Asociación Internacional de Ferias de América, AFIDA, realiza una investigación sobre la industria de ferias y eventos de 18 países (Argentina, Bolivia, Brasil, Colombia, Chile, Cuba, Costa Rica, Ecuador, El Salvador, Guatemala, Honduras, México, Nicaragua, Panamá, Paraguay, Perú, Uruguay y Venezuela).

Durante el año 2010, la región realizó 1.479 eventos. Brasil y México ocuparon los dos primeros lugares con 402 y 401 respectivamente. A continuación, Argentina, Colombia y Perú con 293, 170 y 38 ferias respectivamente. En porcentaje, el $28 \%$ se llevan a cabo en Brasil, $27.5 \%$ en México, $16.28 \%$ en Colombia, $12.36 \%$ en Argentina y $4 \%$ en Perú. Estos 5 países desarrollan el $87 \%$ de la actividad ferial del continente. En toda la región, las ferias de construcción y/o ingeniería lideran el mercado con el 4.96\% (57 exhibiciones), le siguen alimentos $\mathrm{y} / \mathrm{o}$ bebidas con 4.87\% (56 exhibiciones). Esta gran concentración de la actividad ferial en los sectores económicos tradicionales, crea una gran oportunidad para los sectores no tradicionales.

Las tendencias de futuro en el sector ferial en América Latina deben tener en cuenta los siguientes factores:

- Compromiso público -privado para el desarrollo de infraestructuras adecuadas y generación de destinos atractivos para los negocios

- Profesionalización de la actividad, incentivando la innovación y la competencia entre operadores

- Generación de cultura ferial entre los empresarios, los gremios profesionales y los gobiernos. 


\section{Gestión de la comunicación 2.0 en las organizaciones feriales}

La eclosión de la web 2.0 y las redes sociales ha creado un nuevo escenario en la que los ciudadanos (consumidores y clientes) son más colaborativos y participativos. Los cambios de la Web 2.0 han sido tremendamente importantes, ya que no se han quedado únicamente en un entorno tecnológico sino que han conllevado significativos cambios sociales. En este escenario, es preciso lograr que la participación en las ferias y salones profesionales sea una experiencia gratificante. Para ello, las organizaciones feriales tienen que relacionarse con sus públicos utilizando las nuevas herramientas digitales que permiten una comunicación directa e interactiva.

Las ferias ofrecen una excelente oportunidad para el contacto cara a cara con múltiples colectivos vinculados de una forma u otra a facilitar el cumplimiento de los objetivos empresariales: clientes actuales y futuros, intermediarios actuales y futuros, accionistas, proveedores, competidores, empleados, Gobierno y sociedad en general. Presentan, pues, grandes posibilidades para conseguir contactos de calidad en un corto período de tiempo. Las redes sociales ofrecen la posibilidad de complementar esa relación directa entre los distintos actores y públicos feriales, con unos medios basados en la conversación, la implicación y el compromiso de las distintas partes, con un tratamiento de igual a igual. Es posible que el futuro de los eventos feriales online se mueva alrededor de los «mundos virtuales» donde empresas y consumidores viven una realidad alternativa (Molina y Cuesta, 2008 : 152).

Los avances tecnológicos de los últimos años han provocado tal transformación en la sociedad que su influencia en la gestión de la comunicación empresarial es irreversible. Un sitio web significa un mayor acercamiento a los clientes y una comunicación directa con los públicos que puedan precisar de servicios feriales. Esta presencia en Internet es totalmente compatible con el salón real, 
pues el espacio virtual viene a ser un complemento para mejorar el servicio ofrecido a expositores y visitantes. Se trata de constituir un referente para una serie de empresas y profesionales, donde puedan realizar negocios, pero que también responda a sus intereses e inquietudes.

En la actualidad, la práctica totalidad de las organizaciones feriales tiene, al igual que muchas otras empresas, una página web en la que facilitan información de sus servicios para expositores, visitantes y periodistas. Sin embargo, no todas están dispuestas a "conversar" en igualdad de condiciones con los demás actores sectoriales. Deben de asumir que los mercados son, cada vez más, conversaciones e interconexión en redes, por lo que la organización ya no tiene el control absoluto sobre los mensajes. En la nueva era de la participación, los usuarios ya no quieren limitarse a recibir información, sino que quieren interactuar y formar parte activa de proceso comunicativo. Veamos las características de estos espacios virtuales.

\begin{tabular}{|l|c|c|}
\hline \multicolumn{3}{|l|}{ Tabla no 1: CARACTERÍSTICAS DE LAS WEBS FERIALES } \\
\hline & AFE/ APFC & AFIDA \\
\hline Tienen mapa web & $30,2 \%$ & $40 \%$ \\
\hline Tienen buscador interno & $39,5 \%$ & $45 \%$ \\
\hline Con espacio específico para periodistas & $83,7 \%$ & $60 \%$ \\
\hline Con notas de prensa emitidas & $81,4 \%$ & $55 \%$ \\
\hline Permite descargar fotografías & $69,7 \%$ & $45 \%$ \\
\hline Boletín on line & $34,8 \%$ & $40 \%$ \\
\hline Con enlaces externos & $86,1 \%$ & $55 \%$ \\
\hline Permiten descargar audio y vídeo & $27,9 \%$ & $30 \%$ \\
\hline Sindicación de contenidos & $11,6 \%$ & $15 \%$ \\
\hline Participa en redes sociales, foros o & $20,9 \%$ & $50 \%$ \\
\hline blogs & & \\
\hline
\end{tabular}

Fuente: Elaboración Propia a partir de las webs de los miembros de AFE y AFIDA 
Sólo el 30,2\% de las webs de las organizaciones feriales ibéricas tienen un mapa web y un $39,5 \%$ un buscador interno, que son dos de las herramientas fundamentales para lograr que los usuarios puedan encontrar lo que buscan con fluidez y en el menor tiempo posible. Estos datos, son superiores en Latinoamérica, donde el $40 \%$ tiene un mapa web y el $45 \%$ un buscador interno.

Las cifras de los servicios específicos para periodistas son significativamente más altas, en ambos territorios. En general, son claramente superiores en la Península Ibérica. Así, el $83,7 \%$ de las webs españolas y portuguesas tienen un espacio diferenciado para profesionales de la información, frente al $60 \%$ de las de AFIDA; un $81,4 \%$ ofrece un archivo con las notas de prensa emitidas (frente al 55\%) y un 69,7\% presenta la posibilidad de bajar fotografías (frente al 45\%). El único apartado donde las ferias latinoamericanas ofrecen una cifra superior en servicios para los periodistas es en la publicación de un newsletter o boletín online con información sobre la organización y los eventos feriales, el $40 \%$ frente al $34,8 \%$ en el caso español/portugués.

Cabe destacar el $83,6 \%$ de las webs feriales ibéricas que incluyen enlaces externos, frente al $55 \%$ de las latinoamericanas. Las webs ya no deben pretender ser el destino único de la navegación de los usuarios, sino un lugar de encuentro, de enlace con otros contenidos, un espacio dinámico y colaborativos que facilite otras fuentes de información relacionadas con ese sector. Este tipo de web no pierde usuarios, pues éstos volverán al comprobar que se ofrece información actualizada y de calidad.

Las webs americanas registran cifras superiores a la hora de ofrecer contenidos de audio y vídeo para ser descargados por el usuario, el $30 \%$ frente el 27,9\%; y la sindicación de contenidos, el 15\% frente al 11,6\%. Esta es una herramienta clave para que tanto los periodistas como los potenciales expositores y visitantes de un salón conozcan las actualizaciones informativas y las novedades que se van produciendo. 
El dato más significativo es el referido a las redes sociales, mientras el $50 \%$ de los organizadores feriales latinoamericanos forman parte de alguna comunidad online, sólo lo hace el $20,9 \%$ de los organizadores feriales españoles y portugueses. Las cifras registradas indican que la utilización de las redes sociales por parte de los organizadores feriales europeos está en una fase embrionaria, pero es fundamental que sean utilizadas como una herramienta de conversación con sus clientes.

Sólo una de cada cinco organizadores feriales de la Península lbérica participa en alguna red social, lo que indica la escasa utilización de estos espacios digitales como vía de intercambio de información y conocimiento. La red con mayor presencia de entidades del sector ferial es facebook, seguida de twitter, a continuación youtube y con una presencia mínima, flickr, linkedin y otras.

Es muy relevante el uso que los organizadores feriales de España y Portugal realizan de su participación en estos medios sociales, ya que hay una sobresaturación de mensajes propios, sin que se incluya otro tipo de contenidos que puedan añadir valor a sus públicos. Esta forma de actuar denota que todavía no se han adaptado a la forma de participar en redes sociales, basada en la conversación y la interacción en un plano de igualdad. Reproducen modelos de comunicación unidireccional, donde solo tratan de transmitir su mensaje de forma interesada, sin prestar atención a las posibilidades de dialogar e intercambiar contenidos de interés con los diferentes actores del sector.

La situación es relativamente mejor en América Latina, tanto cuantitativamente como cualitativamente, ya que la mitad de las entidades participan en redes sociales y comienzan a entablar un diálogo directo con su audiencia. Los organizadores feriales latinoamericanos tratan de responder a las demandas de sus públicos, organizan sorteos y otras fórmulas de participación e incluyen algunas recomendaciones sobre contenidos sectoriales, pero todavía hay 
críticas que no son respondidas o solicitudes de información que quedan sin atender.

Este análisis viene a demostrar que las políticas comunicativas de las organizaciones feriales están perdiendo oportunidades de superar un modelo de comunicación unidireccional, para dar lugar a fórmulas de interacción basadas en la conversación, el feedback y una mayor participación de sus públicos. Aquí radica el gran potencial para un punto de encuentro sectorial como es un certamen ferial. Una feria dura pocos días, pero gracias a la tecnología y a la participación de las personas a quienes les interesa, puede durar 365 días al año (De la Dehesa, 2010:6).

\section{Herramientas de la web 2.0 en el Bec, Exponor e Ifevi}

El BEC (Bilbao Exhibition Centre) es el sucesor de la antigua Feria Internacional de Muestras de Bilbao. Ocupa los terrenos en los que estaba Altos Hornos de Bizkaia. En el año 2010 generó un impacto económico en términos de Producto Interior Bruto (PIB) de 80.091.771 euros. Durante dicho año se celebraron en sus instalaciones un total de 179 eventos en las áreas de Ferias, BEC Convenciones y Bizkaia Arena, que significaron una ocupación total de 285 días $^{3}$. En el año 2006, el BEC amplió sus instalaciones con un nuevo recinto: el BEC Convenciones, una infraestructura que ha contribuido a la profunda transformación urbana del área metropolitana de Bilbao. BEC forma parte del Comité Ejecutivo y de Dirección de la Unión de Ferias Internacionales (UFI), y es miembro de la Asociación Internacional de Palacios de Congresos (AIPC). Además cuenta con delegaciones en Madrid y Barcelona y tienen representantes en Alemania, Francia, Italia, Polonia, Portugal, Reino Unido, India, Israel, China, Pakistán, Taiwan y Colombia.

La gestión de las relaciones públicas del BEC a través de su web cumple con todas las variables analizadas en este estudio. Tanto en la parte referida al

\footnotetext{
${ }^{3}$ Recogido de http://www.bilbaoexhibitioncentre.com consultado el 8 de septiembre de 2011.
} 
espacio y los servicios específicos para los profesionales de la información, como en lo referente a la utilización de las posibilidades de la web 2.0, el recinto vasco está en vanguardia del aprovechamiento de todas estas potencialidades. Es preciso destacar una zona multimedia, que incluye un boletín digital, un canal de televisión on line, los perfiles en redes sociales (facebook y twitter), un canal en you tube, la sindicación de contenidos e, incluso, un servicio específico para móviles.

EXPONOR - Feria Internacional de Porto es una institución cuya experiencia en la organización de eventos se remonta a 1856. Posee delegaciones en diferentes puntos del mundo y realiza más de 50 ferias anuales de distintos sectores en Europa, África y América del Sur, que congregan anualmente miles de expositores y visitantes. EXPONOR pertenece a una de las entidades de mayor notoriedad en el país, la Asociación Empresarial de Portugal - Cámara de Comercio e Industria fundada en 1849. Es miembro de la UFI (The Global Association of the Exhibition Industry) desde 1991 y actualmente 17 de sus ferias ostentan el sello de garantía internacional. Su página web cumple el noventa por ciento de las variables analizadas. No tiene mapa web, porque, consideran que si el site precisa un mapa es que no está bien organizado 4 . Respecto a la web del BEC, el organizador ferial portugués hace una apuesta más decidida por las redes sociales, ya que además de Facebook y Twitter, dispone de perfiles en Flickr y Linkedln.

El Instituto Ferial de Vigo (IFEVI) registra cerca de cien eventos y una afluencia de público que ronda el millón de visitantes al año. Establecido en 1999, el IFEVI nació con vocación de servicio a los sectores profesionales y sociales de la Eurorregión Galicia-Norte de Portugal. Es preciso tener en cuenta que este recinto se centra en el alquiler de sus instalaciones para la organización de ferias y eventos y no en la organización de los mismos, como ocurre con BEC y Exponor.

\footnotetext{
${ }^{4}$ Declaraciones de Manuel de Sousa, Director de comunicación y marketing de Exponor.
} 
El espacio web de IFEVI cumple el setenta por ciento de las variables analizadas, sin embargo no tiene mapa web, no cuenta con sindicación de contenidos, ni permite descargar audio/vídeo o disponer de un canal en you tube. Las prestaciones online son menores que las de BEC y Exponor, pero mejores que la media de los recintos feriales de AFE, APFC y AFIDA.

Si comparamos las webs de estos tres recintos con sus homólogas de la Península Ibérica y de América Latina observamos que recogen tanto los servicios específicos para periodistas y medios (al igual que las webs peninsulares) como las nuevas prestaciones 2.0 (webs latinoamericanas). Son conscientes de que la reputación on line es tan importante como la presencia en los medios convencionales (Montes, 2010 :39).

Hace ya tiempo que las organizaciones feriales se percataron que su espacio web debía disponer de un área específica para prensa y medios de comunicación, que tenía que estar disponible antes, durante y después del evento (Caballero, 2010). Ahora, comienzan a darse cuenta de que es preciso incorporar servicios de diálogo directo con sus públicos. Ya no basta con informar, con dar a conocer los proyectos. Hay que interactuar con el público mediante estrategias específicas de relaciones púbicas en los medios sociales. El hasta ahora receptor de las comunicaciones se ha convertido en emisor de información. De valiosa información. Con esta participación, desde el punto de vista psicosociológoico, puede haber un aumento de la implicación emocional del público con la institución y con el evento. La relación entre la eficacia de la comunicación y la emoción debe ser considerada.

Los recintos feriales tienen que mantener una comunicación activa con sus clientes: expositores y visitantes. Tradicionalmente los programas de relaciones públicas de los organizadores feriales han estado dirigidos fundamentalmente a los medios de comunicación, de una manera unidireccional y centralizada. Ahora es preciso avanzar para convertirse en una comunicación adaptada en función de los intereses de cada público, con cierto grado de personalización y 
abierta al diálogo. El objetivo es establecer canales de comunicación directa, para que todos los stakeholders de un determinado sector puedan recibir personalmente la información y puedan expresar su opinión o solicitar una respuesta.

\section{Resultados y Conclusiones}

El desarrollo de la globalización, internet, la web 2.0 y las redes sociales son elementos que han producido numerosas transformaciones en la gestión de la comunicación. Las organizaciones deben superar un modelo de comunicación unidireccional y lineal, para dar lugar a procesos basados en la retroalimentación, en la que los públicos tengan cada vez un mayor protagonismo. Para lograrlo, hay que crear contenidos de calidad y diferenciarse del resto. Ya no es suficiente con tener presencia en Internet es preciso participar en la vida de la red.

Las webs analizadas ofrecen fundamentalmente información estática en lugar de una opción más participativa, que incremente la visibilidad en los medios y permita mayor involucración de sus públicos. La gestión de la comunicación por parte de los organizadores feriales todavía está prioritariamente orientada a satisfacer las necesidades de información de los medios informativos, que son concebidos como el intermediario natural para hacer llegar los mensajes a la opinión pública. Así, el $83,7 \%$ dispone de un espacio específico para periodistas y todas ofrecen notas de prensa, imágenes o vídeos para descargar. Sin embargo, ha llegado el momento de dar un paso más e iniciar una conversación directa con clientes y audiencias.

La comparación de los espacios webs de los miembros AFE, APFC y AFIDA indica que las ferias españolas y portuguesas prestan una mayor atención a la hora de ofrecer un espacio específico y servicios diferenciados para los periodistas y los medios de comunicación, mientras que las latinoamericanas registran una mayor utilización de las herramientas que ofrece la web 2.0, con 
especial mención a las redes sociales. No obstante la participación en redes sociales, tanto por parte de los organizadores feriales de la Península lbérica (20\%) como de América Latina (50\%), todavía es insuficiente. Además, su uso se centra fundamentalmente en intentar transmitir de forma unidireccional su mensaje, sin que haya un diálogo real en un plano de igualdad. Los organizadores feriales no suelen contestar a las demandas de información y, mucho menos, a las críticas a su gestión.

Por todo ello, consideramos que la mayoría de los espacios en Internet de las organizaciones feriales españolas/portuguesas y latinoamericanas no están aprovechando las posibilidades que ofrece la web 2.0. Aunque en una feria física la interactividad es un elemento esencial, en la presencia en Internet no se apuesta por la comunicación multidireccional, sino todo lo contrario, se utiliza un proceso comunicativo unidireccional.

Las ferias virtuales en sentido estricto aún están por llegar. Hasta el momento la presencia de los organizadores feriales en la Red se centra en servir como complemento a las ferias tradicionales. No es suficiente con colocar unos contenidos para mantener la presencia en Internet durante todo el periodo interferial, sino que las ferias virtuales deben convertirse en un canal de comunicación permanente con los medios, las empresas y profesionales de ese ámbito. Para ello es necesario dar un mayor protagonismo a la cercanía, a la proximidad, a la participación y a la conversación.

\section{Bibliografía}

Acerenza, M.A. (2006), Marketing en Ferias Turísticas, Sevilla, Editorial Trillas/Mad, 2006.

Baamonde, X. (2009), A Comunicación no Sector Feiral. Estratexias de organizadores, expositores e visitantes profesionais, Pontevedra, Edicións Fervenza.

Baamonde, X.; Galindo, F. y Lorenzo, J. (2008), "Dimensiones comunicativas de ferias y certámenes", en VV.AA., Laberinto Visual, Málaga, Círculo de Estudios Visuales, pp. $235-262$ 
Berné, C. y García, M., "La eficacia de la exposición en Ferias: extensión del Modelo de Hansen", en Análisis de la Actividad Ferial en Aragón. Aplicación a Ferias Pofesionales, Universidad de Zaragoza, 2004.

Bonoma, T. V., "Get More Out of Your Trade Shows", Harvard Business Review, ํㅜ 61, (January - February), 1983, pp. 75-83.

Caballero, R. (2010). "La web del evento", en Mundo ferial, año XXVII, № 158, sep.-oct., pp. 14 y 15

Carrio, F. (2001), "Nuevas herramientas tecnológicas en la promoción ferial”, III Congreso de Ferias Españolas, Las Palmas, AFE, pp. 45-48

Cevera Taulet, A.; Franco Borderia, A. y García Esquembre, M. (2001), "Entorno ferial español y análisis de las ferias españolas mediante la técnica del Benchmarking", en Revista Valenciana D'estudis Autonomics, no 36, pp. 131-153.

De la Dehesa, A. (2010), "Resiliencia 2.0", revista Expone, № 28

García Pérez de Lema, D., Madrid Guijarro, A. y Munuera Alemán, J.L. (2008), "Crecimiento, endeudamiento y rentabiidad de las instituciones feriales en España", Revista Información Comercial Española ICE, ํo 840, ene.feb., pp. 105-122

Hansen, K. (1996), "The dual motives of participants at international trade shows: an empirical investigation of exhibitors and visitors with selling motives", International Marketing Review, Vol. 13, oㅡ 2, pp. 39-54

Jaen, F. (1995), El Negocio Ferial. Privatizar, Vender , Rentabilizar, Barcelona, Dictext.

Jiménez, J.F., y Pemartín, M. (2008) "Análisis de la actividad ferial en España: la perspectiva sectorial de una década (1995-2005)", Revista Información Comercial Española ICE, ํㅡ 840

Jiménez, J.F.; Cazorla, I.M.; y Linares, E. (2002), "Ferias Comerciales en España. Un análisis sectorial”, en Distribución y Consumo, año 12, ํo 61, pp. 61-71.

Kim, Y. K. (2005): «Korean Exhibitors' Behavior in Overseas Exhibitions», Working Paper, University of Nevada, Las Vegas. 
Larragañaga, A. (2005), "La organización de las ferias con la aplicación de las nuevas tecnologías en el márketing ferial", en las /I Jornadas de Marketing Ferial, Madrid, 7 de abril.

Latorre, J. L. (1990), Ferias y Exposiciones en el Exterior: Manual Práctico, Madrid, Instituto Español de Comercio Exterior.

Le Monnier, F. (1994), Marketing Ferial: Como gestionar y rentabilizar la participación en salones profesionales, Barcelona, Ed. Gestión 2000

Lucas, F. (2004), "Las ferias y la promoción de las ciudades", en el I Congreso de Citymarketing, Elche.

Mayaux, F.; Shaw, J. y Tissier-Desbordes, E. (2006): «Les Foires et Salons: Pour Quoi Faire? Objectifs des Exposants et Mesure de l'efficacité», Décisions Marketing, 41, páginas 23-32.

Mesonero de Miguel, M. M. y Garmendia Aguirre, F. (2004), "Comunicaciones integradas feriales o cómo planificar con éxito una feria industrial", en Revista de Dirección y Administración de Empresas, № 11, marzo, pp. 109-129.

Molina, F.J., y Cuesta, P.J., (2008) "Las ferias comerciales y el marketing electrónico: un análisis comparativo", Revista Información Comercial Española ICE, ㄲo 840, pp. 141-153.

Montes, A. (2010). "Tendencias: estrategias de gestión 2.0”, revista Expone, oㅡ 28, pp. 36-39

Mottard, E. (2002), "Como comunicar en una feria", en Marketing y Ventas, oㅡ 175, Decembro, pp. 6-11.

Munuera, J.L.; Hernández, M. y Ruíz, S. (1999), "Trade Fairs as Services: a look a Visitors' Objetives in Spain”, Journal of Business Research, no 44, pp. 17-24.

Muñiz, R. (2002), "La Red trae otras ferias", en Revista MK, Marketing + Ventas, ano oㅜ 17, № 167, pp. 48-53

Navarro, F. (2001), Estrategias de Marketing Ferial, Madrid, ESIC.

Pérez del Campo, E. (2002), La Comunicación fuera de los medios, Bellow the line, Madrid, Esic Editorial. 
Puchalt, J. (2008) "La actividad ferial en el contexto europeo", Revista Información Comercial Española ICE, ํㅜ 840, ene.-feb.

Puchalt, J. (2001), Las ferias comerciales como instrumento de marketing al servicio de las empresas: una aplicación a Feria de Valencia, Tesis doctoral, Universitat de Valencia, Facultad de Economía, Valencia.

Rico, J.C. (2005), La exposición comercial. Tiendas y escaparatismo, stands y ferias, grandes almacenes y superficies, Gijón, Ediciones Trea, S.L.

Rojas, O. (2007), Web 2.0 - Manual (no oficial) de uso, Madrid, Esic Editorial.

Sáiz, M.A. (2005), "Las ferias virtuales", II Jornadas de Marketing Ferial, Madrid, abril.

Sashi, C. M. y Perretty, J. (1992): «Do Trade Shows Provide Value?», Industrial Marketing Management, 21, páginas 249-55.

Stevens, R. P. (2005): Trade show and Event Marketing, Mason, Thomson y American Marketing Association

Tanner, J.(2002), "Leveling the playing field: factors influencing trade show success for small companies", Industrial Marketing Management, vol. 31, 2002, pp. 229-239.

Triviño, Y. (2006), Gestión de eventos feriales. Diseño y organización, Madrid, Editorial Síntesis,

Werner, A. F., (2008), Transparencia y el gobierno electrónico. Dos herramientas del buen gobierno en el proceso de democratización, Razón y Palabra, no 61, México

\section{Para citar este artículo:}

Baamonde Silva, Xosé Manuel - Galindo Arranz, Fermín - Marinho, Jorge (20-06-2012). ESTRATEGIAS DE COMUNICACIÓN 2.0 EN EL MERCADO FERIAL DE ESPAÑA, PORTUGAL Y AMÉRICA LATINA.

REDMARKA - CIECID - Unidad de Investigación en Marketing Aplicado-Universidad de A Coruña

Año V, Número 8, V2, pp.89-112

ISSN 1852-2300

URL del Documento : cienciared.com.ar/ra/doc.php? $n=1666$

URL de la Revista : cienciared.com.ar/ra/revista.php?wid=39

REDMARKA UIMA-Universidad de A Coruña - CIECID 